\title{
A agricultura familiar no Brasil: um retrato do desequilíbrio regional
}

\author{
Arlindo Kamimura* \\ Aline de Oliveira** \\ Geraldo F. Burani*
}

Recebido em 3/6/2010; revisado e aprovado em 29/6/2010; aceito em 30/6/2010

\section{Introdução}

A recente publicação do Censo Agropecuário 2006 pelo Instituto Brasileiro de Geografia e Estatística (IBGE) (2009) deu início a uma série de trabalhos, cujo objetivo é a apresentação e interpretação dos resultados dessa pesquisa, em geral comparando-os com os dados do Censo Agropecuário 1995/ 1996. Em função do conteúdo altamente suscetível às diferentes interpretações de caráter político-ideológico é razoável supor que acirrados embates com elevada carga emotiva serão promovidos pelos diversos setores da sociedade, cada qual argumentando e procurando demonstrar seus pontos de vista, antes que um consenso embasado numa análise científica e metodológica seja aceito e avalizado pela academia. Dados analisados separadamente ou examinados sob uma ótica parcial, sem o contexto geral, podem induzir a conclusões errôneas, como disse o economista Ronald Coase, em Tullock G. (2001): "If you torture the data long enough, it will confess".

Mesmo correndo o risco mencionado, o objetivo deste trabalho é analisar alguns dados pertinentes à agricultura, em particular da agricultura dita Familiar, em dois instantes cobertos pelos citados Censos - o de 1995/1996 e o de 2006, e contribuir para que o citado consenso seja alcançado.

A polêmica já se inicia na própria definição de Agricultura Familiar (AF), distintas metodologicamente, nestes dois Censos, além da não coincidência do período coberto por essas pesquisas, tornando inviável uma comparação direta. Entretanto, já o Censo 95/96 mostra de forma inequívoca a grande disparidade econômica existente entre as várias regiões brasileiras, principalmente no tocante à produtividade e à rentabilidade por hectare dessas regiões. Isso é mostrado no estudo Projeto de Cooperação Técnica INCRA/ $F A O$, coordenado por Guanziroli e Cardim (2000), no qual uma definição de AF é estabelecida. O documento apresenta uma exaustiva fotografia da $\mathrm{AF}$, mostrando os desequilíbrios e comparando-a com a Agricultura Patronal nas várias regiões do Brasil. Já o Censo 2006 deu origem ao documento MDA (2006), do Ministério de Desenvolvimento Agrário, no qual os critérios utilizados para definição de AF estão na Lei 11.326 de $24 / 7 / 2006$, mais restritivos na abrangência em relação ao universo definido pela metodologia INCRA/FAO. Todavia, com a utilização dos microdados do Censo 2006 é possível a recuperação dos indicadores comparativos da AF 2006, sob os mesmos critérios INCRA/FAO (FRANÇA et al., 2009), permitindo uma análise evolutiva, tendo sempre em mente a distinção existente nos períodos de coleta dos dados nos dois Censos.

Não é objeto deste trabalho um estudo rigoroso do ponto de vista acadêmico das variáveis causadoras dos desequilíbrios regionais conhecidos ad nauseam há muito, mesmo porque a escassez de informações confiáveis não permite uma análise estatística aceitável. É inegável e intuitivo, no entanto, a importância dos aspectos culturais, do

\footnotetext{
* PPGE/IEE/USP - Programa de Pós-graduação em Energia, Instituto de Eletrotécnica e Energia - Universidade de São Paulo. Av. Prof. Luciano Gualberto, 1289 - Cidade Universitária - 05508-900 - São Paulo, SP, Brazil. Tel. (55)(11)3091-2629 - fax (55)(11) 3816-7828. E-mail: kamimura@iee.usp.br

** Universidade Federal do Tocantins, TO, doutoranda do PPGE/IEE/USP - Programa de Pós-graduação em Energia, Instituto de Eletrotécnica e Energia - Universidade de São Paulo, SP, Brasil e bolsista da ANP - Agência Nacional do Petróleo..
} 
grau de escolaridade, do nível de formação e utilização tecnológica, das variáveis econômicas, da pluviometria e do clima associados às regiões brasileiras nos resultados positivos e negativos da agricultura como um todo. A falta de uma política consistente e perseverante de desenvolvimento econômico e social para as regiões mais pobres do país solidificou uma falácia passivamente aceita pela grande parcela da população: uma teoria fatalista da história, a exemplo daquela descrita por Leon Tolstói em Guerra e Paz, na qual o livre-arbítrio e atitudes não têm relevância no inevitável e determinístico processo de permanência da pobreza endêmica para essas regiões. As fotografias obtidas dos Censos 95/96 e 2006 mostram, felizmente, que a realidade pode ser diversa dessa atitude conformista e que a quebra de paradigmas e falácias depende tão somente da vontade política da sociedade na condução do processo histórico.

Essa postura não conformista, historicamente presente em muitos segmentos da sociedade, ganha um marco na história brasileira com a promulgação da Constituição de 1988, na qual os problemas sociais associados à área rural, origem e foco de parcela significativa da dinâmica da pobreza nacional são objetivamente enfrentados, inicialmente, com as leis de Custeios e Benefícios de 1991 e efetivadas a partir de 1992, consolidando-se, entre 1996 e 2006. Assim, não apenas a Universalização da Previdência Social, mas uma série de ações dirigidas e desenvolvidas nas áreas rurais são causadores de uma mudança significativa no contexto socioeconômico. A partir de então, leis, projetos, programas e políticas têm início: a criação da Cédula do Produto Rural (CPR) (1994), o Programa de Fortalecimento da Agricultura Familiar (PRONAF) (1995), o Programa de Geração de Emprego e Renda Rural (PROGER Rural) (1995), a garantia de preços agrícolas (96), o Programa de Securitização da Dívida (1995) dado ao elevado endividamento do setor, Programa Especial de Saneamento de Ativos (PESA) (1998), a criação da Cédula da Terra e Banco da Terra (97/98) e regulamentados em 2001, com a respectiva criação de assentamentos sob responsabilidade do INCRA, intensificados a partir de 1995, a Lei Kandir, de incentivo à exportação (1996), a introdução dos contratos de opção de venda e do Prêmio de Escoamento de Produtos (PEP), a Moderfrota (1999) para modernização e mecanização agrícola, a criação do Ministério do Desenvolvimento Agrário (MDA), inicialmente por medida provisória (1999) e confirmada por decreto (2004), Lei da Armazenagem (2000), a Garantia de Safra (2002), o Programa de Aquisição de Alimentos (PAA) (2003), o Programa Nacional de Desenvolvimento de Territórios Rurais (PRONAT) (2003), novos títulos de apoio ao financiamento como o Certificado de Depósito Agropecuário e a Lei Warrant Agropecuário CDA/WA (2004), Seguro Agricultura Familiar (Proagro Mais) (2004), Programa Nacional do Biodiesel (2004), o Programa Bolsa Família (2004) e o II Plano Nacional de Reforma Agrária (2003/04) vêm contribuídos de forma decisiva e assimétrica, do ponto de vista regional, para o desenvolvimento da agricultura e, em particular, da Agricultura Familiar.

\section{Material e Métodos}

Além dos Censos Agropecuários 1995/ 96 e 2006 do IBGE, dois relatórios baseados nesses Censos nortearam este trabalho: os acima citados (GUANZIROLI; CARDIM, 2000; FRANÇA et al., 2009), nos quais são encontradas as diferentes definições da AF segundo os dois critérios: o Projeto de Cooperação Técnica INCRA/FAO e a Lei n. 11.326, assim como são apontadas as diferenças concernentes aos intervalos de tempo cobertos pelos Censos (ano safra e ano civil). As principais diferenças nas definições da $\mathrm{AF}$ se referem à área do estabelecimento, à caracterização do rendimento das atividades, à mensuração dos trabalhos familiares e contratados, de forma que os critérios FAO/ INCRA são mais abrangentes que a Lei 11.326. Para ilustrar essas diferenças, pode-se citar, por exemplo: a área total ocupada pela AF no Brasil, em 2006, segundo a Lei 11.326 é de 80,3 milhões de hectares, responsável por um Valor Bruto da Produção (VBP) de 54.367,7 milhões de reais, enquanto sob o critério INCRA/FAO esses números são respectivamente de 106,8 milhões de hectares e 57.572,2 milhões de reais. Essas diferenças conduzem a uma rentabilidade 
por hectare da AF no Brasil, em valores correntes de 2006 , de $\mathrm{R} \$ 677,10 /$ ha, no primeiro caso, e R\$539,10/ha, no segundo.

Neste trabalho, em benefício da coerência, consideraremos somente a definição da Agricultura Familiar, segundo os critérios do INCRA/FAO.

\subsection{O Censo Agropecuário de 1995/96}

O extenso relatório do Projeto de Cooperação Técnica INCRA/FAO (op. cit.) fornece um quadro da chamada Agricultura Familiar, mostrando, entre os vários resultados, a tabela 1 obtida a partir do Censo 1995/96.

Tabela 1 - Agricultura Familiar - Número de estabelecimentos, Área, VBP, Financiamentos totais e Rentabilidade por hectare em Reais de 1996 (R\$ 96/ha).

\begin{tabular}{|c|c|c|c|c|c|}
\hline REGIÃO & $\begin{array}{c}\text { mil } \\
\text { N. estab. }\end{array}$ & $\begin{array}{c}\text { mil ha } \\
\text { Área }\end{array}$ & $\begin{array}{c}(10)^{\wedge} \text { 6 R\$ 96 } \\
\text { VBP }\end{array}$ & $\begin{array}{c}\text { mil R\$ 96 } \\
\text { Financ. Tot. }\end{array}$ & $\begin{array}{c}\text { R\$ 96/ha } \\
\text { Rentab. }\end{array}$ \\
\hline NE & $2.055,2$ & $34.043,22$ & $3.026,90$ & 133.973 & 88,91 \\
CO & 162,1 & $13.691,31$ & $1.122,70$ & 94.058 & 82,00 \\
N & 380,9 & $21.860,96$ & $1.352,66$ & 50.123 & 61,88 \\
SE & 633,6 & $18.744,73$ & $4.039,48$ & 143.812 & 215,50 \\
S & 907,6 & $19.428,23$ & $8.575,99$ & 515.862 & 441,42 \\
BR & $4.139,4$ & $107.768,45$ & $18.117,73$ & 937.828 & 168,12 \\
\hline
\end{tabular}

Fonte: Guanziroli C. E. e Cardim S. E. de C. S. (2000)

A rentabilidade da $\mathrm{AF}$, definida, neste trabalho, como sendo o Valor Bruto da Produção (VBP) correspondente à $\mathrm{AF}$ dividida pela área total ocupada pela $\mathrm{AF}$, mostra uma grande diferença para a região Sul em relação às outras regiões, principalmente Norte, Centro-Oeste e Nordeste, configurando um retrato do desequilíbrio histórico apontado na introdução deste trabalho. As causas deste desequilíbrio, se por um lado são convincentes e fáceis de apontar de maneira genérica, a exemplo das citadas na introdução, são difíceis de provar estatisticamente, em função da escassez de dados fidedignos e ausência de série histórica. Algumas evidências, no entanto, podem ser levantadas e fornecer uma pista no sentido de estabelecer quais fatores ou variáveis afetam a rentabilidade da AF. As Figuras de (1) a (8) mostram, de forma autoexplicativa, a rentabilidade ( $\mathrm{R} \$$ /ha) para o ano de 1996 nas ordenadas e algumas variáveis sociais, econômicas e tecnológicas cotejadas nas abscissas, para as regiões brasileiras. Como pode ser observado, existe um comportamento sistemático e coerente nessas curvas, evidenciando uma correlação entre a rentabilidade e as variáveis escolhidas, corroborando os resultados esperados, percebidos de forma intuitiva pelo senso comum. Sendo a rentabilidade (R\$/ ha) a ordenada em todas as Figuras (1) a (8), as correspondentes variáveis nas abcissas serão:

- Figura 1: Percentual da população rural da correspondente região, acima de 4 anos e com menos de 1 ano de escolaridade.

- Figura 2: Financiamentos totais para a AF da região por hectare.

- Figura 3: Investimentos totais para a AF da região por hectare.

- Figura 4: Percentual dos estabelecimentos de AF da região que utilizam assistência técnica.

- Figura 5: Percentual dos estabelecimentos de $\mathrm{AF}$ da região que utilizam energia elétrica.

- Figura 6: Percentual dos estabelecimentos de AF da região que utilizam adubos e corretivos de solo.

- Figura 7: Percentual dos estabelecimentos de $\mathrm{AF}$ da região que utilizam técnicas de correção de solo.

- Figura 8: Percentual dos estabelecimentos de $A F$ da região que utilizam força só mecânica mais tração animal.

A região Sul, de longe em primeiro lugar, seguida pela região Sudeste são as regiões que detêm os valores mais favoráveis nas variáveis escolhidas e, portanto, as 
maiores rentabilidades por hectare na $\mathrm{AF}$, confirmando as expectativas.

Embora os dados completos não estejam ainda disponíveis, a região Nordeste foi a região mais beneficiada pelas políticas, pro-

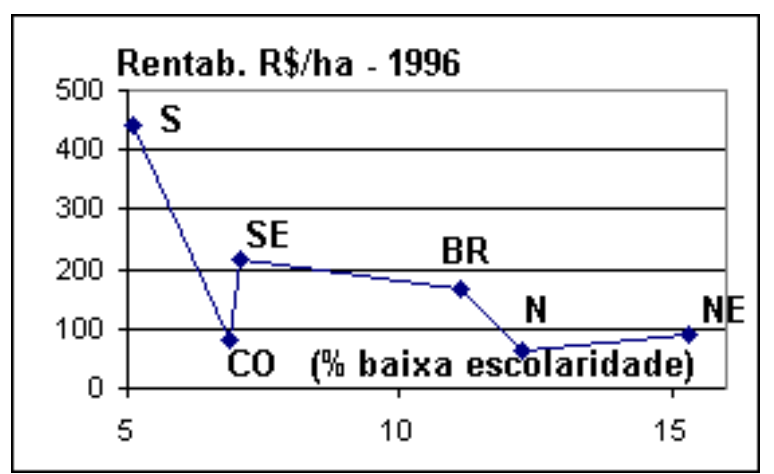

Figura 1 - Rentabilidade versus percentual da população rural da correspondente região, acima de 4 anos e com menos de 1 ano de escolaridade.

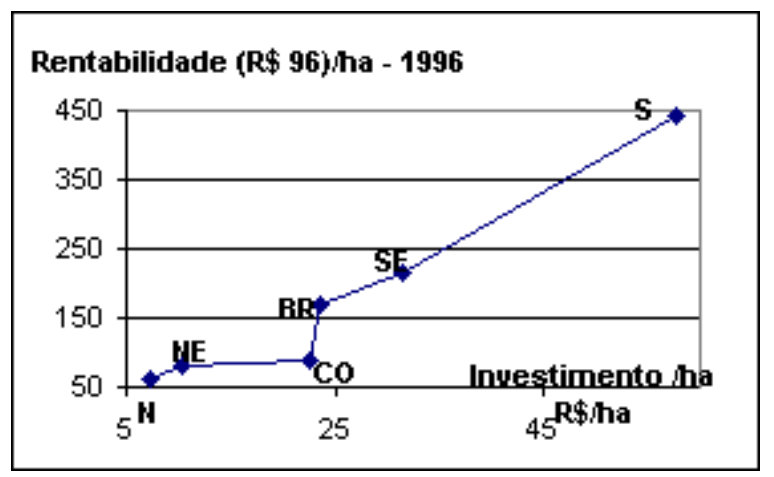

Figura 3 - Rentabilidade versus investimentos totais para a $\mathrm{AF}$ da região por hectare.

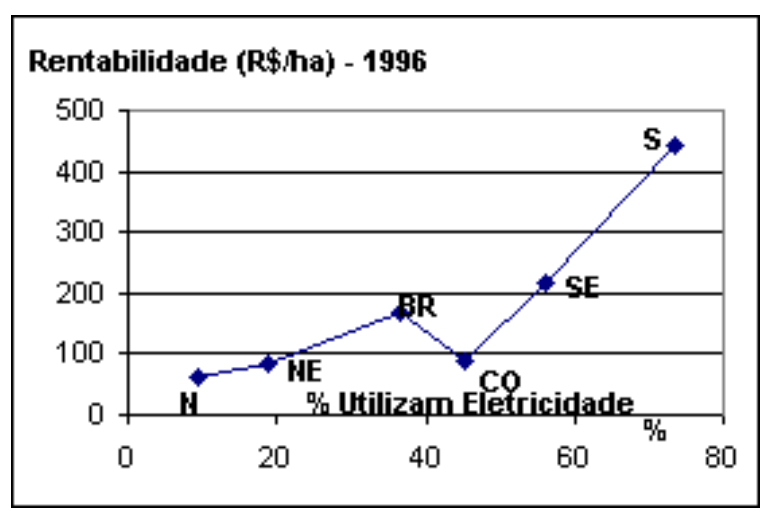

Figura 5 - Rentabilidade versus percentual dos estabelecimentos de $\mathrm{AF}$ da região que utilizam energia elétrica. gramas e ações governamentais durante o período correspondente aos dois Censos, escolha justificada pela situação socioeconômica e climática associada à região.

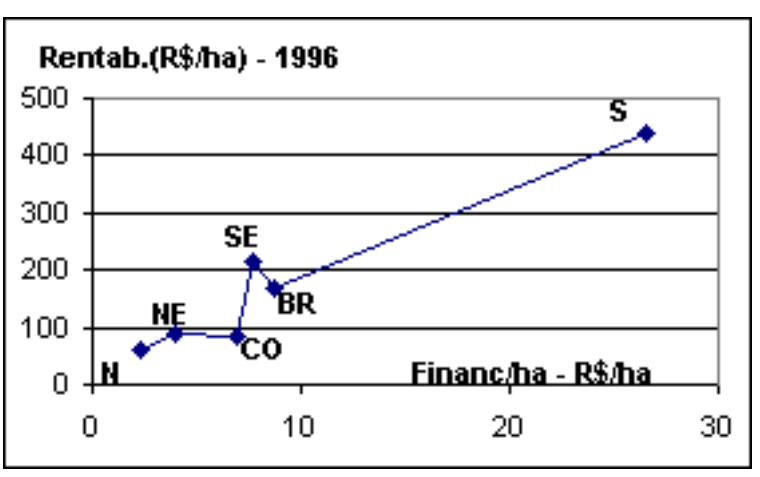

Figura 2 - Rentabilidade versus financiamentos totais para a $\mathrm{AF}$ da região por hectare.

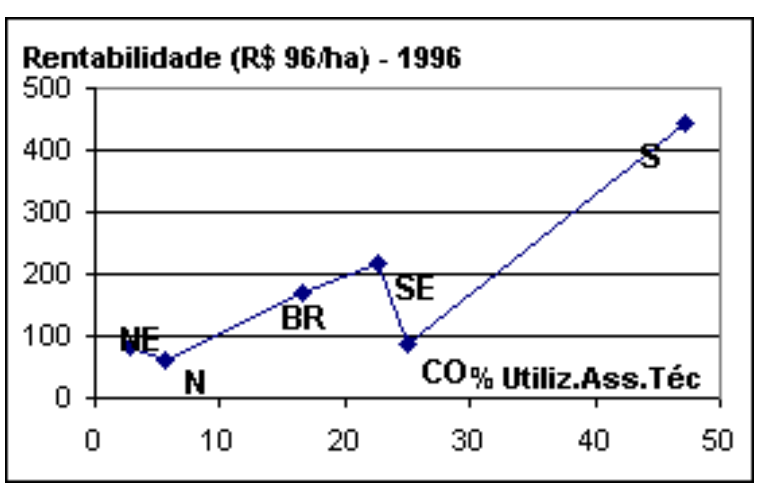

Figura 4 - Rentabilidade versus percentual dos estabelecimentos de $\mathrm{AF}$ da região que utilizam assistência técnica.

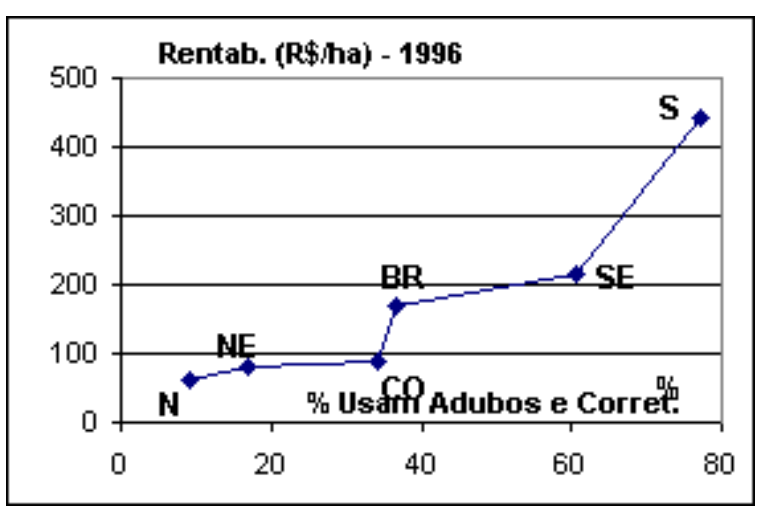

Figura 6 - Rentabilidade versus percentual dos estabelecimentos de $\mathrm{AF}$ da região que utilizam adubos e corretivos de solo. 


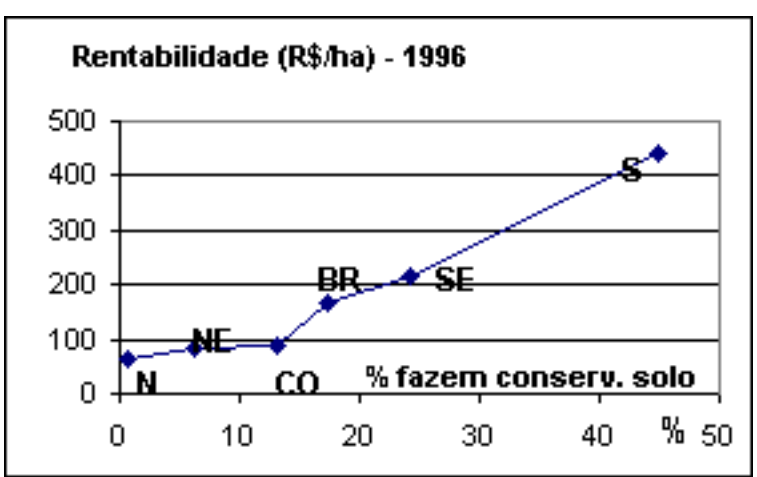

Figura 7 - Rentabilidade versus percentual dos estabelecimentos de $\mathrm{AF}$ da região que utilizam técnicas de correção de solo.

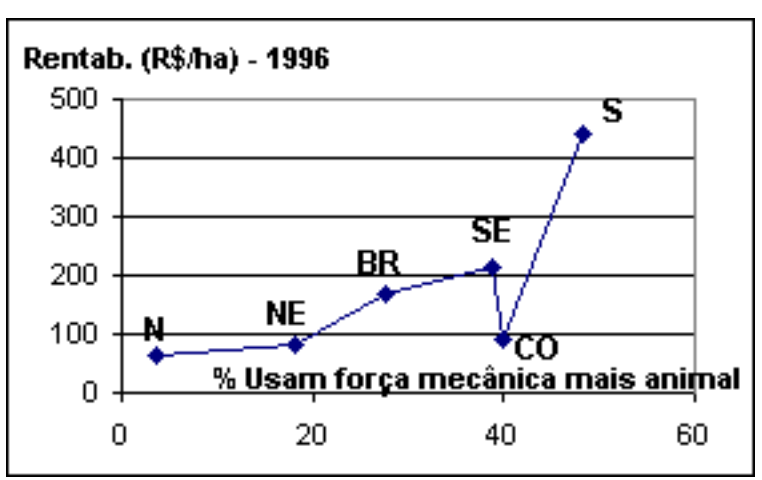

Figura 8 - Rentabilidade versus percentual dos estabelecimentos de $\mathrm{AF}$ da região que utilizam força só mecânica mais tração animal.

Fonte: Elaboração a partir de Guanziroli C. E. e Cardim S. E. de C. S. (2000) e IBGE (2010)

\subsection{O Censo Agropecuário de 2006}

A tabela 2 mostra a evolução da rentabilidade real ( $\mathrm{R} \$$ 96/ha) da AF nas várias regiões do país. Os valores monetários de 2006 foram corrigidos para os valores de 1996 pelo Índice Geral Preços de Mercado da Fundação Getúlio Vargas - IGPM/FGV. A escolha deste índice foi devido à complexa e pulverizada estrutura de suprimento e consumo, muitas vezes estabelecidos internamente à $\mathrm{AF}$, resultando em um largo espectro das componentes representativas da inflação deste segmento.

Tabela 2 - Agricultura familiar: valor bruto da produção (milhões R\$96), área (milhões hectares), rentabilidade ( $\mathrm{R} \$ 96 / \mathrm{ha})$.

\begin{tabular}{|c|c|c|c|c|c|c|c|}
\hline REGIAO N & VBP & ÁREA & Rtbdade & REGIAO NE & VBP & ÁREA & Rtbdade \\
\hline $1995 / 96$ & 1352,7 & 21,9 & 61,9 & $1995 / 96$ & 3026,9 & 34 & 88,9 \\
\hline 2006 & 1567,5 & 22,4 & 69,9 & 2006 & 5822 & 35,2 & 165,3 \\
\hline REGIAO $S$ & & & & REGIAO SE & & & \\
\hline $1995 / 96$ & 8576 & 19,4 & 441,4 & $1995 / 96$ & 4039,5 & 18,7 & 215,5 \\
\hline 2006 & 9180,8 & 18,2 & 505,8 & 2006 & 4478,4 & 16 & 279,6 \\
\hline REGIAO CO & & & & $\mathrm{VBP}=$ & \multirow{3}{*}{\multicolumn{3}{|c|}{$\begin{array}{l}\text { EM }(10)^{\wedge} 6 \text { Reais Cte de } 1996-\mathrm{R} \$ 96 \\
\mathrm{EM}(10)^{\wedge} 6 \text { (ha) } \\
\mathrm{EM}(\mathrm{R} \$ 96) /(\mathrm{ha})\end{array}$}} \\
\hline $1995 / 96$ & 1122,7 & 13,7 & 82 & ÁREA = & & & \\
\hline 2006 & 1343,5 & 15 & 89,9 & Rtbdade $=$ & & & \\
\hline
\end{tabular}

Fonte: Elaboração a partir de Guanziroli C. E. e Cardim S. E. de C. S. (2000) e FRANÇA C. G. et al. (2009).

O crescimento real da rentabilidade da AF na região Nordeste foi de $85,9 \%$ entre 1996 e 2006, correspondendo a uma taxa anual de $6,4 \%$ ao ano. Essa taxa foi muito acima da taxa de crescimento das demais regiões e também da AF do Brasil, que foi de $24,8 \%$ ou $2,2 \%$ ao ano. As demais regiões tiveram os respectivos crescimentos reais no período ou taxa anual: região Centro-Oeste de $9,6 \%$ e $0,9 \%$ ao ano; região Norte de $13 \%$ e $1,2 \%$ ao ano; região Sudeste de $29,7 \%$ e $2,6 \%$ ao ano e finalmente a região Sul, tradicionalmente com as maiores taxas, de $14,6 \%$ e $1,4 \%$ ao ano, demonstrando um sinal de esgotamento do seu potencial de expansão. As razões desses crescimentos da rentabilidade por hectare nas várias regiões do país, além das apontadas e ilustradas na seção 2.1, através das Figuras (1) a (8), se devem, também, a outros fatores que foram identificados 
pelos autores, no decorrer de vários trabalhos elaborados em diferentes estados pelo Instituto de Eletrotécnica e Energia da Universidade de São Paulo - IEE/USP (BURANI et al., 2008, 2009, 2009, 2009, 2009, 2009): os programas, projetos e ações citados na introdução tiveram como consequência, não apenas resultados relacionados com a produtividade da $\mathrm{AF}$, mas também induziram uma grande transformação na estrutura de distribuição, consumo, destino final e qualidade dos produtos, tais como a merenda escolar, redes municipais de abastecimento, o Programa Nacional de Biodiesel, o Agroturismo e outros, que aumentaram o espaço de comercialização e o valor agregado desses produtos. Além desses fatores, deve-se destacar também o aumento real do preço de alguns produtos agropecuários, na década em questão, motivado principalmente pelo crescimento das exportações.
Supondo, por hipótese, que essas taxas de crescimento anual permaneçam inalteradas para os anos posteriores a 2006, para as respectivas regiões brasileiras, as rentabilidades por hectare (em Reais de 96/ha) evoluirão, segundo a figura 9, na qual fica explicitada o forte crescimento do Nordeste diante de outras regiões e ao Brasil, tal que a rentabilidade se iguala: ao do Sudeste em 2021, à equivalente rentabilidade do Sul (de 1996), em 2024, e alcançando o próprio Sul, em 2029. Somente neste ano de 2029, a rentabilidade do Sudeste alcança a rentabilidade equivalente da região Sul de 1996. Complementando a análise, as rentabilidades das regiões Norte e Centro-Oeste permanecem bastante abaixo das demais regiões, não alcançando sequer a rentabilidade da região Sul de 1996, neste século, perpetuando o paradigma da pobreza endêmica regional.

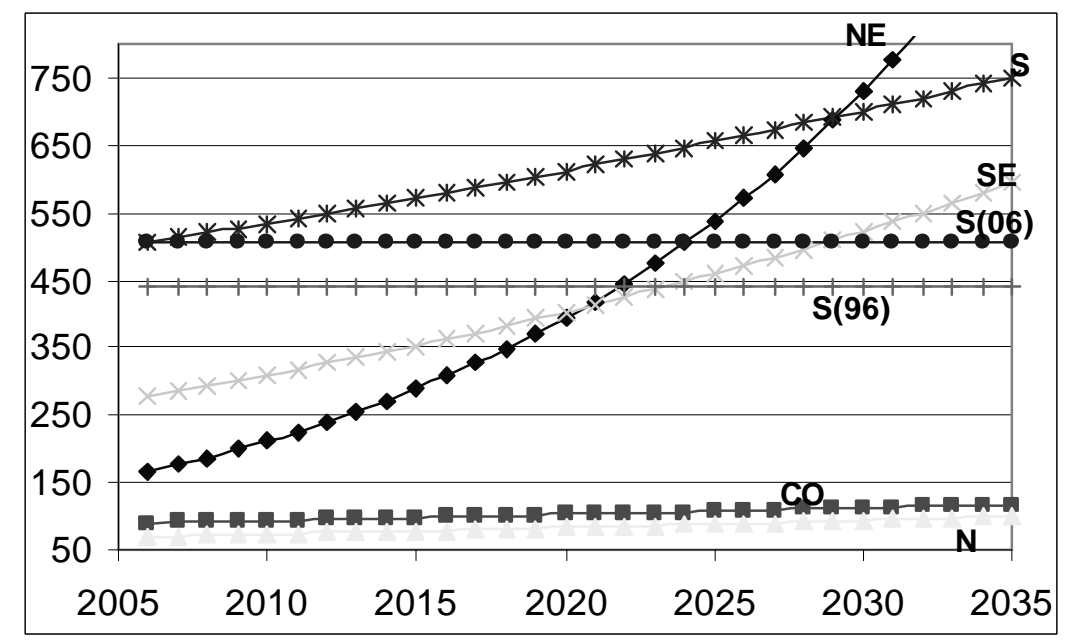

Figura 9 - Agricultura Familiar: evolução das rentabilidades em reais constantes de 1996 por hectare, nas regiões brasileiras.

Fonte: Elaboração a partir de Guanziroli C. E. e Cardim S. E. de C. S. (2000) e França C. G. et al. (2009).

\section{Conclusão}

A publicação do Censo Agropecuário 2006 deu início a vários trabalhos comparativos em relação ao Censo Agropecuário 1995/96 sobre a AF no Brasil, que devem vir a público proximamente, mostrando em detalhes a evolução deste segmento na década considerada. O objetivo deste trabalho é também mostrar alguns resultados preliminares baseados nestes Censos: o cotejamento das rentabilidades por hectare da AF, evi- denciando o forte desequilíbrio existente entre as várias regiões do país, bem como identificar algumas causas deste desequilíbrio.

O que é evidenciado neste trabalho é a transformação qualitativa da AF do Nordeste entre 1996 e 2006, que no início rasteja com outras regiões pobres do país, alcança índices de crescimento muito superiores, no final do período, aos índices de regiões com $\mathrm{AF}$ tradicionalmente pujantes, a ponto de, mantida a tendência, suplantá-los em poucos anos, quebrando o velho paradigma da pobreza endêmica. 


\section{Referências}

BURANI G. F. et al. Balanço energético do Tocantins, 2007, ano base 2006. São Paulo: IEE/USP - Instituto de Eletrotécnica e Energia da Universidade de São Paulo, 2008. ISBN 978-85-86923-14-2.

Balanço energético do Maranhão, 2008, ano base 2007. São Paulo: IEE/USP - Instituto de Eletrotécnica e Energia da Universidade de São Paulo, 2009. ISBN 97885-86933-16-6.

. Estudo de cenários energéticos para o estado do Ceará. São Paulo: IEE/USP - Instituto de Eletrotécnica e Energia da Universidade de São Paulo, 2009. ISBN 97885-86923-22-7.

Estudo da projeção da matriz energética do Maranhão 2030. São Paulo: IEE/USP - Instituto de Eletrotécnica e Energia da Universidade de São Paulo, 2009. ISBN 97885-86923-18-0.

Estudo da projeção da matriz energética do Ceará 2030. São Paulo: IEE/USP - Instituto de Eletrotécnica e Energia da Universidade de São Paulo, 2009. ISBN 97885-86923-20-3.

. Estudo de cenários energéticos para o Estado do Maranhão. São Paulo: IEE/USP - Instituto de Eletrotécnica e Energia da Universidade de São Paulo, 2009. ISBN 978-85-86923-17-3.
CENSO AGROPECUÁRIO IBGE (1995/96). Disponível em: <http://www.ibge.gov.br>.

CENSO AGROPECUÁRIO IBGE (2006). Disponível em: <http://www.ibge.gov.br>.

FRANÇA C. G. et al. O censo agropecuário 2006 e a agricultura familiar no Brasil. 2009. Disponível em: <http:// mineiropt.com.br/arquivosestudo/ arq4b10179787f8b.pdf>.

GUANZIROLI, C. E.; CARDIM, S. E. C. S. Novo retrato da agricultura familiar: o Brasil redescoberto. Projeto de Cooperação Técnica INCRA/FAO, MDA Ministério do Desenvolvimento Agrário, Brasília, DF: INCRA/FAO, MDA, 2000. Disponível em: <www.INCRA.gov.br/ fao $>$.

IBGE - Instituto Brasileiro de Geografia e Estatística, 2010. Disponível em: <http:/ /www.sidra.ibge.gov.br>.

MDA - Ministério do Desenvolvimento Agrário. Agricultura familiar: primeiros resultados. Brasília, DF: MDA, 2009. Disponível em: <http://www.ibge.gov.br>.

TULLOCK G. A comment on Daniel Klein's 'A Plea to Economists Who Favor Liberty'. Eastern Economic Journal, v. 27, n. 2, Spring 2001, note 2 (Text: As Ronald Coase says, 'if you torture the data long enough it will confess'. Note: I have heard him say this several times. So far as I know he has never published it). 